\title{
JURNAL
}

MANAJEMEN PENDIDIKAN

Volume 07 Nomor 02 Juli 2019

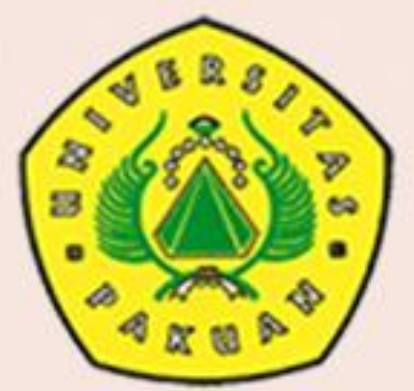




\section{TIM EDITORIAL}

\section{EDITOR IN CHIEF}

1. Dr. Rais Hidayat

\section{REVIEWER}

1. Prof. Dr. Bibin Rubini, M.Pd.

2. Prof. Dr. Anna Permanasari, M.Si.

3. Prof. Dr. Thamrin Abdullah. MM., M.Pd.,

4. Prof. Dr. Marzuki ,M.Ed., M.A.,

5. Dr. Indarini Dwi Pursitasari,

6. Dr. Eri Sarimanah,

7. Dr. Bambang Sumintono,

8. Dr. Rhini Fatmasari,

9. Dr. Chaerul Rochman,

10. Dr. Risda Amini,

11. Dr. Idam Ragil Widianto Atmojo,

12. Dr. Erni Murniarti,

13. Dr. Irvan Permana, M.Pd.,

14. Dr. Eka Suhardi,

15. Dr. Henny Suharyati,

16. Dr. Griet Helena Laihad,

17. Dr. Rita Retnowati,

18. Dr. Endang Poerwanti, M.Pd.,

19. Dr. Abdul Muktadir,

20. Dr. Fitri Indriani,

21. Dr. Yuyun Elizabeth Patras
Universitas Pakuan, Bogor, Indonesia

Universitas Pakuan, Indonesia
Universitas Pendidikan Indonesia, Indonesia
Universitas Pakuan, Indonesia
Universitas Tanjungpura, Indonesia
Universitas Pakuan, Indonesia
Universitas Pakuan, Indonesia
University of Malaya, Malaysia
Universitas Terbuka, Indonesia
Universitas Islam Negeri Sunan Gunung Djati
Universitas Negeri Padang, Indonesia
Universitas Sebelas Maret, Indonesia
Universitas Kristen Indonesia, Indonesia
Universitas Pakuan, Indonesia
Universitas Pakuan, Indonesia
Universitas Pakuan, Indonesia
Universitas Pakuan, Indonesia
Universitas Pakuan, Indonesia
Universitas Muhammadiyah Malang, Indonesia
Universitas Bengkulu, Indonesia
Universitas Ahmad Dahlan, Indonesia
Universitas Pakuan, Indonesia

\section{EDITOR}

1. Didit Ardianto,

2. Sulfikar Sallu,

3. Desti Herawati,

4. Oding Sunardi,

5. Herfina,

6. Yudhie Suchyadi,

7. Yeyen Suryani,

8. Non Dwishiera Cahya Anasta,

9. Moh. Ali,

10. Iskandar,

11. Donna Sampaleng,

12. Dian Wulandari,

13. Huriah Rachmah,

\section{LAYOUT EDITOR \& IT SUPPORT}

1. Aries Maesya

2. Agung Prajuhana Putra

3. Windu Gata,

4. Agung Prajuhana Putra,

5. Muhamad Ginanjar Ganeswara,

6. Rizki Agung Dwihantoro,

7. Ade Irwan,
Universitas Pakuan, Indonesia

Universitas Sembilanbelas November Kolaka, Indonesia Universitas Pakuan, Indonesia Universitas Pakuan, Indonesia Universitas Pakuan, Indonesia Universitas Pakuan, Indonesia Universitas Kuningan, Indonesia Universits Pendidikan Indonesia, Indonesia Institut Agama Islam Negeri (IAIN) Palu, Indonesia Universitas Tadulako, Indonesia Sekolah Tinggi Teologi IKAT Jakarta, Indonesia Universitas Pakuan, Indonesia Universitas Islam Bandung, Indonesia

Universitas Pakuan, Indonesia Universitas Pakuan, Indonesia STMIK Nusa Mandiri, Indonesia Universitas Pakuan, Indonesia Universitas Pakuan, Indonesia Universitas Pakuan, Indonesia Universitas Pakuan, Indonesia 


\section{DITERBITKAN OLEH :}

SEKOLAH PASCASARJANA

JURNAL MANAJEMEN PENDIDIKAN

e-ISSN : 2614-3313

p-ISSN : 2302-0296

Universitas Pakuan, Bogor - Indonesia

\section{ALAMAT :}

Gedung Sekolah Pascasarjana, Universitas Pakuan,

Jalan Pakuan No 1, Ciheuleut, Kelurahan Tegalega, Kecamatan Bogor Tengah, Kota Bogor Indonesia - 16143

No. Telp. : +622518320123

No. Fax. : + +62251 8320123

e-mail : jmp@unpak.ac.id

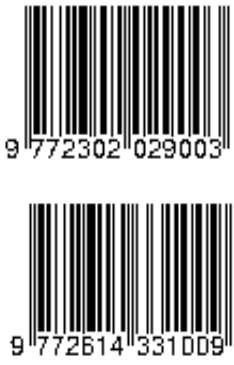




\section{Dari Editor}

\section{Selamat Datang di Jurnal Manajemen Pendidikan.}

Jurnal Manajemen Pendidikan adalah jurnal yang menerbitkan Artikel ilmiah di bidang manajemen pendidikan dan administrasi pendidikan. Jurnal ini diterbitkan oleh Sekolah Pascasarjana, Universitas Pakuan, Bogor. Jurnal ini memberikan kesempatan bagi para penulis ilmiah/peneliti dalam bidang manajemen pendidikan dan administrasi pendidikan untuk menerbitkan artikelnya. Kebijakan dari tim editor adalah hanya artikel yang terkait dengan bidang manajemen pendidikan dan administrasi pendidikan yang akan dipublikasikan secara online. Publikasi secara daring akan menambah kekayaan informasi dan pengetahuan ilmiah yang diperoleh terutama dari penelitian. Jurnal ini diterbitkan dua kali dalam satu tahun, didokumentasikan dengan baik dalam bentuk jurnal, yang mencakup berbagai artikel manajemen pendidikan dan administrasi pendidikan oleh penulis dari berbagai latar belakang. Selain itu, kami juga memiliki mitrabestari dari Universitas Pakuan beserta dari beberapa universitas lain yang kompeten meninjau setiap artikel sebelum dipublikasikan. Setiap artikel yang diterbitkan dalam Jurnal ini akan bermanfaat bagi semua pengunjung dan pembaca.

\section{Pengindeksan}

Crossref

On E Search

\section{Cagaruda PKP|INDEX Goggle}

publons

\section{$R \partial A D=\infty$ Dimensions}

\section{Perangkat Artikel}

\section{turniting) EndNote G grammarly (요 MENDELEY}

\section{Menggunakan gaya kutipan APA}

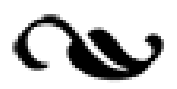

APA

STYLE 


\section{DAFTAR ISI}

PENGEMBANGAN MODEL RESIPROCAL, EXAMPLE NON EXAMPLE, DAN MIND MAPPING (REXMIND) UNTUK MENGOPTIMALISASI HASIL PEMBELAJARAN ILMU PENGETAHUAN SOSIAL (IPS) DI KELAS VII

Sri Sariningsih, Adi E Yusuf, Entis Sutisna, Griet Helena Laihad

PENINGKATAN ORGANIZATIONAL CITIZENSHIP BEHAVIOR MELALUI PENGEMBANGAN KEPEMIMPINAN TRANSFORMASIONAL DAN KEPUASAN KERJA

$778-789$

Arwan Gunawan, Widodo Sunaryo, Hari Muharam

PENINGKATAN KREATIVITAS GURU MELALUI PENGEMBANGAN SUPERVISI KEPALA SEKOLAH DAN IKLIM ORGANISASI

790-799

Riyadhel Ghifar, Adi E Yusuf, Sumardi Sumardi, Farida Wulandari

MENINGKATKAN KUALITAS PENDIDIKAN MELALUI KEBIJAKAN MANAJEMEN BERBASIS SEKOLAH

DAN TANTANGANNYA

Yuyun Elizabeth Patras, Agus Iqbal, Papat Papat, Yulia Rahman

800-807

PENINGKATAN KOMITMEN PROFESI GURU MELALUI PENGEMBANGAN KEPRIBADIAN DAN

PEMBERDAYAAN

$808-815$

Irma Fitriyanti, Soewarto Hardhienata, Hari Muharam

HUBUNGAN ANTARA BUDAYA SEKOLAH DAN KOMPETENSI PEDAGOGIK DENGAN KREATIVITAS

GURU

Umyati Umyati, Sumardi Sumardi, Eka Suhardi

HUBUNGAN ANTARA KEPEMIMPINAN VISIONER KEPALA SEKOLAH DAN KEINOVATIFAN DENGAN EFEKTIVITAS KERJA GURU

Siti Halimah, Rita Retnowati, Herfina Herfina

PENINGKATAN PRODUKTIVITAS KERJA DOSEN MELALUI PENGEMBANGAN EFEKTIVITAS SISTEM INFORMASI MANAJEMEN DAN BUDAYA ORGANISASI

$833-842$

Annisa Restu Purwanti, Nandang Hidayat, Entis Sutisna

PENINGKATAN EFEKTIVTAS PEMBELAJARAN MELALUI PENINGKATAN KOMPETENSI PEDAGOGIK

DAN TEAMWORK

$843-850$

Arif Fathurrahman, Sumardi Sumardi, Adi E Yusuf, Sutji Harijanto

PENINGKATAN KOMITMEN ORGANISASI MELALUI PENGEMBANGAN BUDAYA ORGANISASI DAN

KEPUASAN KERJA

$851-858$

Dwi Rahmanendra, Eka Suhardi 